\title{
Where the IMA should be: a personal view
}

It gives me great pleasure to write a column for IMA Fungus. The IMA has been without a house periodical since the 1994 issue of IMA News, but is now replaced by a new visionary IMA Fungus. This new periodical will provide current information on a broad spectrum of global mycological activities, from news to research, and also provide a forum for the exchange of ideas on topical issue. It is also hoped that this periodical will differ from others in that it will be more interactive with online mycological information, having hyperlinks to talks, interviews and exciting movie clips. To achieve this goal we are very happy to have secured the services of Prof. dr David Hawksworth as Editor-in Chief, and will also be looking for sub-editors among our younger members to work with us to ensure that IMA Fungus is trendy, and appealing to the youth. This first number of the resurrected newsletter also comes at a time when the existing IMA Officers and Executive Committee has entered its final year in office (Aug. 2006 to Aug. 2010), and as such is also a time for reflection and for gazing into the future.

$\mathrm{T}$ he past few years have seen the IMA make great strides at gaining a better interaction with its membership.

This has chiefly been accomplished via updates provided on its website (www. IMA-Mycology.org), but also through regional meetings, all of the IMA's regional committees and associations have been very active, hosting regular meetings over this period. The IMA also welcomed two new sustaining member organisations, the All Russian Academy of Mycology (www. mycology.ru), and the Mycological Society of China (www.mscfungi.org). Another significant development has been the IMA accepting the ownership of MycoBank (www.MycoBank.org), a freely available, online repository for taxonomic novelties, descriptions, and illustrations. In the coming year this initiative will enter a new phase, as remote curatorship of various fungal groups will now be possible via Citrix software, which will improve the taxonomic opinions expressed in this database, as more mycologists will be asked to assume ownership (curatorship) of various fungal groups. Of course there are also many other excellent online mycological initiatives, and with time, it is hoped that more of these will also be placed under the guardianship of the IMA, to ensure that they remain freely available in support of mycology.

In the coming years the IMA must strive to develop its brand name, and formalize its vision and mission, to adequately solidify its membership base, and distinguish it from other international bodies dealing with fungi. The IMA should remain an impartial overarching organisation that can support mycology globally in all its shapes and forms. It should strive to use its vast membership and network to promote and strengthen mycology worldwide. And to address problems and issues that arise with a unified front and a global perspective, wherever they occur. The IMA represents the world's largest body of mycologists, and as such should also be the body to recognise mycological excellence in individuals internationally, and strive to promote the careers of young mycologists, while simultaneously also acknowledging the contributions made by more established members. It is my hope that in the coming years we can harness the power of our membership to propel our science to where it belongs, to the very top. At the same time it must make inputs to student training, ensuring that this remains vibrant, exciting, and in step with new developments. This will hopefully ensure that there are enough qualified candidates to support all facets of mycology, which remains a huge task of the utmost scientific importance, and economic relevance.

Pedro W. Crous President, IMA

(Utrecht, The Netherlands; p.crous@cbs. knaw.nl)

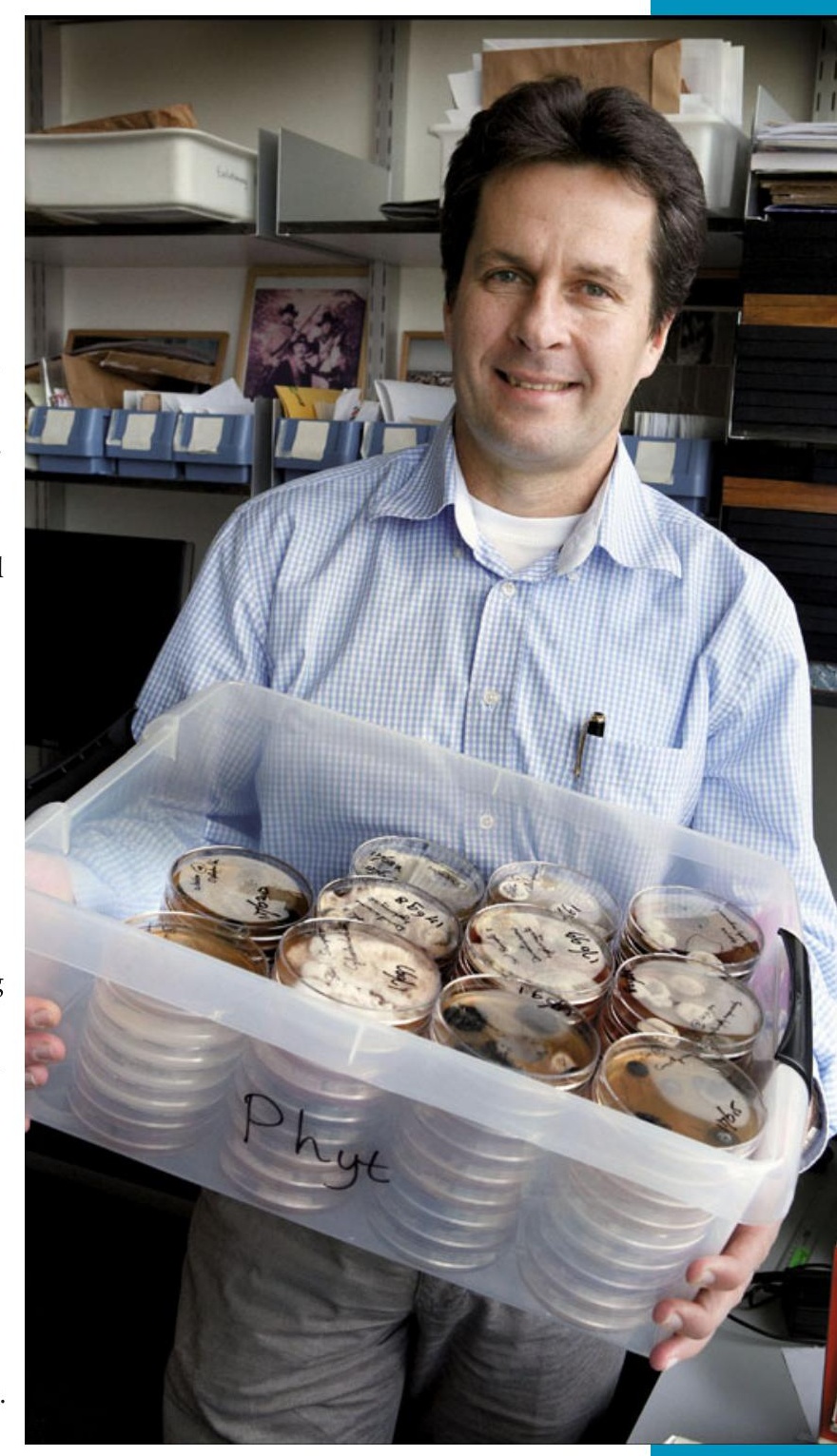

